\title{
REGISTROS DE REPRESENTAC̣ÃO SEMIÓTICA E SUAS CONTRIBUIC̣̃̃ES PARA O ENSINO DE FÍSICA
}

\author{
Cintia Ap. Bento dos Santos* \\ Edda Curi**
}

RESUMO: Este artigo apresenta dados de uma pesquisa que tem por objetivo apresentar como ocorrem as mobilizações de conhecimentos matemáticos na resolução de tarefas de Física, considerando os registros de representação semiótica. Para evidenciar o exposto, trazemos uma análise qualitativa centrada na transformabilidade dos registros de representação semiótica e em aspectos didáticos de três tarefas que fizeram parte de um de nossos instrumentos utilizados na pesquisa, bem como uma síntese explicitando o que Duval entende por registros de representação semiótica. Ao final, apresentamos algumas considerações que apontam para as dificuldades que alunos podem ter no momento da resolução de tarefas de Física que, de certa forma, associam-se com a transformabilidade de um registro de representação semiótica.

Palavras-chave: Mobilização de Conteúdos; Registros de Representação Semiótica; Ensino de Física.

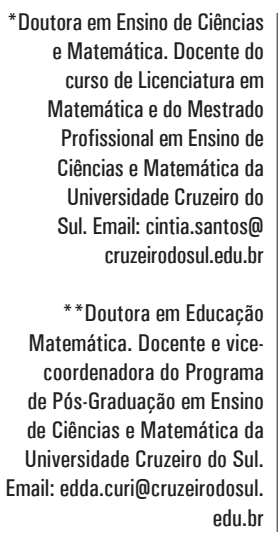

\section{RECORDS OF SEMIOTICS REPRESENTATION AND THEIR CONTRIBUTIONS TO THE TEACHING OF PHYSICS}

ABSTRACT: This article presents data from a research that aims to show how mobilizations of mathematical knowledge occur when solving Physics tasks, considering the records of semiotic representation. To demonstrate the above, we present a qualitative analysis focused on the transformability of the records of semiotic representation of three tasks that were part of one of the instruments used in field research, as well as a summary explaining what they meant by Duval records of semiotic representation. In the end we present some considerations that point to the difficulties students may run into at the time of solving Physics tasks, which are somehow associated with the transformation of a record of semiotic representation.

Keywords: mobilization of contents, records of semiotic representation, teaching Physics. 


\section{INTRODUC̣̃̃O}

Este artigo apresenta dados de uma pesquisa desenvolvida com alunos de um curso de licenciatura em Matemática de uma instituição privada da cidade de São Paulo, em que pretendiamos investigar as potencialidades e as limitações que o domínio matemático gera no ensino de Física. Nossa fundamentação teórica apoiou-se em autores da didática francesa, o que nos possibilitou a visão das dificuldades presentes em tarefas de Física e possíveis indicativos das razões de algumas delas parecerem mais simples do que outras aos estudantes. Verificamos que o grau de dificuldade de tais tarefas pode estar associado ao reconhecimento do objeto matemático, devido a sua representação e, por consequência, a sua transformabilidade.

Nossa pesquisa nasceu de questionamentos e reflexões sobre a seguinte pergunta: "Por que a Física se configura, para os alunos, como uma disciplina de grande dificuldade, em que os conhecimentos aprendidos nas aulas de Matemática parecem não fazer conexão para a resolução de tarefas, quando solicitados?”.

Em alguns casos, quando um aluno não resolve um exercício de Física em que é preciso usar conteúdos matemáticos, não podemos afirmar apenas que não tenha conhecimentos matemáticos suficientes; que encontre dificuldades na interpretação do enunciado; ou que não tenha aprendido nada de Matemática nas séries anteriores. O problema parece bem mais amplo e envolve uma série de aspectos não somente relacionados aos conteúdos matemáticos, mas também de natureza didática, relativos ao conhecimento de um determinado conteúdo.

Para verificar essas considerações, nossos instrumentos de pesquisa foram elaborados à luz do referencial teórico da didática francesa, e conforme mencionamos anteriormente, nossa pesquisa de campo se deu com alunos do curso de licenciatura em Matemática de uma universidade privada da cidade de São Paulo. A pesquisa de campo foi realizada durante um curso optativo, intitulado "Didática e Metodologia do Ensino de Física". Foram trabalhados com os alunos alguns aspectos de teorias da Didática da Matemática e foram aplicados cinco instrumentos de pesquisa que elaboramos, um dos quais analisaremos aqui: "Análise das tarefas quanto às dificuldades de representação".

Elaborado com base no referencial teórico do pesquisador francês Raymond Duval sobre os registros de representação semiótica, esse instrumento foi elaborado com três questões sobre cinemática e apresentava, em sua comanda, as informações para sua realização. Embora não houvesse sido exigido que os alunos resolvessem as tarefas, considerava-se ideal sua resolução, pois o objetivo era que descrevessem as principais dificuldades encontradas com as diferentes representações expostas em cada tarefa, bem como aquelas presentes na resolução. Era preciso, também, que os alunos verificassem se o enunciado facilitava a resolução ou não.

Tal instrumento tinha por objetivos: verificar como os alunos se comportam diante de tarefas que exigem o trabalho com um mesmo objeto matemático, porém, em diferentes registros de representação; constatar em quais tipos de transformações eles apresentam maior ou menor dificuldade; observar como os 
alunos se comportam ao realizarem uma análise didática de tarefas de Física que apresentam a transformabilidade de um mesmo objeto matemático, no caso, a função polinomial de $1^{\circ}$ grau.

Para melhor compreensão do instrumento selecionado e de sua análise, exporemos, no próximo tópico, uma síntese do que Duval (1993, 2009) considera sobre os registros de representação semiótica e seus aspectos de transformabilidade.

\section{SÍNTESE SOBRE OS REGISTROS DE REPRESENTAC̣ÃO SEMIÓTICA}

Para Duval (1993), os registros de representação semiótica são representações referentes a um sistema de significação, ou seja, são uma forma de tornar algo acessível a alguém, comunicando uma ideia que parte de uma formulação mental. Assim, Duval (1993) define as representações semióticas como produções que empregam signos de um sistema de representação. O autor destaca que "uma figura, um enunciado em língua natural, uma fórmula algébrica, um gráfico, são representações semióticas que salientam sistemas semióticos diferentes” (Ibidem, p. 39). Podemos entender que um mesmo objeto matemático, quando apresentado por meio de representações diferentes, não possui o mesmo conteúdo.

Duval (2009) entende que os registros de representação semiótica constituem uma forma de explorar uma informação ou simplesmente comunicá-la a um interlocutor. Existem quatro tipos muito diferentes de registros, que podem ser sintetizados de acordo com a Figura 1.

Figura 1: Classificação dos diferentes registros mobilizáveis no funcionamento matemático

\begin{tabular}{|l|l|l|}
\hline & $\begin{array}{l}\text { REPRESENTAÇÃO } \\
\text { DISCURSIVA }\end{array}$ & $\begin{array}{l}\text { REPRESENTAÇÃO } \\
\text { NÃO DISCURSIVA }\end{array}$ \\
\hline $\begin{array}{l}\text { REGISTROS } \\
\text { MULTIFUNCIONAIS }\end{array}$ & $\begin{array}{l}\text { Língua natural } \\
\text { Associações verbais } \\
\text { (conceituais) }\end{array}$ & $\begin{array}{l}\text { Figuras geométricas planas } \\
\text { ou em perspectiva }\end{array}$ \\
\hline $\begin{array}{l}\text { REGISTROS } \\
\text { MONOFUNCIONAIS: }\end{array}$ & $\begin{array}{l}\text { Sistemas de escritas: } \\
\text { numéricas (binária, decimal, } \\
\text { fracionária...) } \\
\text { algébricas simbólicas } \\
\text { (línguas formais). } \\
\text { Cálculo }\end{array}$ & Gráficos cartesianos \\
\hline
\end{tabular}

Fonte: Duval, 2003

Para Duval (2003), a originalidade da atividade matemática está em mobilizar simultâneamente ao menos dois registros de representação ao mesmo tempo, ou na possibilidade de trocar a todo momento de registro de representação. $\mathrm{Na}$ resolução de tarefas, um registro pode aparecer privilegiado, porém, sempre deve existir a possibilidade de passar de um registro a outro; assim, o autor enfatiza 
que a compreensão, em Matemática, depende da coordenação de ao menos dois registros de representação semiótica. Ele considera, ainda, que as representações semióticas são indispensáveis para fins de funcionamento e mobilização de conteúdos matemáticos, ou seja, não existe mobilização de conteúdos que não esteja associada a representações semióticas.

Duval $(1993,2009)$ considera que para um sistema semiótico poder funcionar como um registro de representação, ele deve assumir, além da comunicação, outras funções, duas das quais, importantes em termos cognitivos, são as transformações de conversão e de tratamento.

Em relação à transformação de tratamento, Duval (1993) define que essa é uma atividade cognitiva que visa à transformação de uma representação semiótica em outra, porém, com o mesmo registro de representação, como por exemplo a resolução de uma equação ou sistemas de equações; e afirma que "o tratamento é uma transformação interna a um registro" (Ibidem, p. 41). Já a transformação de representação, chamada de "conversão", consiste na mudança entre o registro de partida e de chegada, porém, conservando o mesmo objeto matemático. Como exemplo, podemos mencionar a passagem da escrita algébrica de uma equação à sua representação gráfica, ou mesmo da representação gráfica para a escrita algébrica.

A teoria de Duval $(2003,2009)$ possibilita a reflexão a respeito do fato de uma tarefa proposta poder ser entendida quando apresentada no registro figural, mas oferecer dificuldades se expressa por meio do registro em língua natural ou mesmo simbólico, pois as funções cognitivas a serem mobilizadas são diferentes em cada tipo de registro. Essas observações nos remetem a dificuldades que podem ser encontradas pelos educandos nas tarefas de Física, uma vez que a maioria delas apresenta seu enunciado no registro da língua natural, porém, sua resolução exige a passagem para o registro figural (mesmo que de forma mental) e ainda necessita do registro no sistema de escrita. Duval considera que "a passagem de um enunciado em língua natural a uma representação em outro registro toca um conjunto complexo de operações para designar os objetos" (DUVAL, 2003, p.18).

\section{ANÁLISE DAS ATIVIDADES QUANTO A SUA TRANSFORMABILIDADE: TRATAMENTO E CONVERSÃO}

Reiteramos que as análises das atividades que passaremos a apresentar fazem parte de um instrumento de pesquisa ${ }^{1}$ elaborado com três tarefas, e cada uma se relaciona a um tipo de transformação.

Nossa metodologia para análise das questões porpostas neste instrumento se apoiou no método qualitativo, em que buscamos analisar tanto os procedimentos de resolução dos alunos em relação à transformabilidade das representações semióticas, bem como as dificuldades que encontram no domínio matemático ao resolverem tarefas de Física. Nossa análise também considerou a abordagem didática que os alunos transcreveram em relação a cada tarefa apresentada. 
A tarefa 1, transcrita na Figura 2, apresenta seu enunciado na língua natural e fornece, inclusive, a representação gráfica. Solicita a função horária da velocidade representada pelo gráfico, ou seja, é necessário, a partir desses dois registros fornecidos, construir o registro algébrico.

Figura 2: Comanda da tarefa 1 do instrumento

1. É dado o gráfico de um ponto material que se movimenta numa trajetória retilínea. Escreva a função horária da velocidade representada por este gráfico.

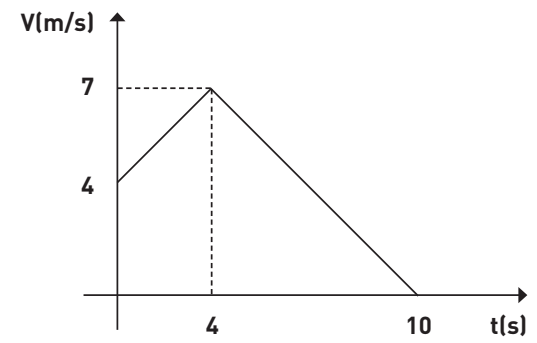

Fonte: Adaptado de Bonjorno et al., 200

A transformação que ocorre em uma tarefa como essa é a conversão, pois o objeto matemático continua a ser o mesmo; o que muda é seu registro de representação. Consideramos também que o aluno precisava ter conceitos adquiridos sobre a cinemática, a fim de identificar que o gráfico apresentaria duas funções horárias distintas, uma no intervalo de 0 a $3 \mathrm{~s}$ e outra no intervalo de $3 \mathrm{~s}$ a 10s, por tratar-se de um gráfico do Movimento Uniforme. Nossa hipótese era de que os alunos teriam maior dificuldade na resolução dessa tarefa, uma vez que a conversão, ou seja, a passagem do registro gráfico para o registro algébrico, já não é uma ação tão imediata. Neste caso, a resolução não é técnica: é necessário certa adaptação para que os alunos mobilizem os conteúdos.

Ao considerarmos as respostas dos alunos, constatamos que a maior dificuldade era extrair as informações do gráfico e representá-las na forma algébrica; ou seja, a conversão necessária, neste caso, quando se necessita realizar a passagem da representação gráfica para representação algébrica, parece não ser uma transformação imediata para os alunos, o que dificulta o entendimento da questão e o êxito da resolução. Além disso, também confirma, em tarefas de Física que envolvem as representações, o que Duval $(2003$, 2009) considera para a Matemática: representações diferentes de um mesmo objeto suscitam dificuldades para os alunos, pois não apresentam, de forma alguma, o mesmo conteúdo.

No caso da passagem de um gráfico para uma representação algébrica, apesar de falarmos do mesmo objeto matemático — neste caso, a função afim ou função polinomial de primeiro grau —, um dos problemas identificados nessa conversão é a institucionalização habitual que a conversão tem para os alunos, no seguinte sentido: a partir de uma função, elaborar um gráfico, e não o sentido inverso. 
Esse sentido considerado inverso, apesar de utilizar o mesmo objeto matemático, não tem o mesmo significado para os alunos. Aqui podemos retomar Duval (2009) que afirma que representações diferentes de um mesmo objeto matemático apresentam conteúdos diferentes, ou seja, são situações diferentes trabalhar um gráfico e uma expressão algébrica, embora representem o mesmo objeto matemático.

Nos protocolos dos alunos, apresentados nas próximas figuras, é possível verificar a dificuldade que apresentam em passar para o registro algébrico a partir do registro gráfico.

Figura 3: Reprodução do protocolo da tarefa 1 do $\mathrm{A003}$

0 enunciado acima dificulta a resolução da tarefa, tornando o exercício disponível à compreensão do aluno, fazendo com que ele manipule as informações para, então, resolver. Obs.: Sair do gráfico para função dificulta a compreensão imediata do aluno.

Fonte: Arquivo da pesquisadora

Figura 4: Reprodução do protocolo tarefa 1 do A007

Minha maior dificuldade, a princípio, foi entender o problema, a fórmula a ser usada.

Fonte: Arquivo da pesquisadora

Figura 5: Reprodução do protocolo da tarefa 1 do A004

Tenho uma grande dificuldade, ainda, em entender o que se pede nos enunciados. Portanto, para mim, o enunciado está dificultando muito para que eu consiga desenvolver o problema proposto.

Fonte: Arquivo da pesquisadora

Nos protocolos dos alunos, fica claro, embora reconheçam o objeto matemático e verifiquem a necessidade de extrair do gráfico as funções horárias da velocidade de cada movimento fornecido em seu intervalo de tempo, que apresentam dificuldades em utilizar a representação mais adequada. Ou seja, a dificuldade em compreender o enunciado, mencionada pelos alunos, nada mais é do que a dificuldade de transformar o registro da língua natural em registro algébrico.

Com base na análise desses protocolos, podemos verificar as dificuldades dos alunos, e fica evidente que o problema pode não estar associado ao conhecimento de um conteúdo matemático, e sim ao reconhecimento de um objeto matemático em diferentes registros de representação. Às vezes, como professores de Matemática, imaginamos que determinadas conexões são simples para os alunos, quando, na verdade, podem não ser. Aqui podemos relacionar o que Duval (2009) considera a esse respeito: a passagem de um sistema de representação para outro pode ser fator frequente e familiar na atividade matemática, porém, não tem nada de evidente e espontâneo para a maioria dos alunos.

Para a tarefa 2, apresentada na Figura 6, fornecemos o registro algébrico conjuntamente com o intervalo de tempo do deslocamento e solicitamos aos 
alunos o registro gráfico desse mesmo objeto matemático, ou seja, o deslocamento do móvel.

Figura 6: Comanda da tarefa 2 do instrumento 3

2. Um móvel realiza um movimento retilíneo e uniforme obedecendo à função horária $S=40-10 \mathrm{t}$ (no SI). Construa o gráfico dessa função no intervalo de 0 a $4 \mathrm{~s}$.

Fonte: Adaptado de Bonjorno et al., 2001

Nossa hipótese era de que os alunos teriam menor dificuldade para a resolução dessa tarefa, uma vez que a transformação, mesmo sendo, neste caso, uma conversão, consiste em uma ação mais imediata e rotineira para alunos: a passagem do registro algébrico para o registro gráfico, uma transformação de conversão que imaginamos não apresentar o mesmo grau de dificuldade da conversão inversa. Fica evidente, no protocolo dos alunos, que para essa tarefa o custo cognitivo da resolução é mais imediato em relação às mobilizações necessárias. Tais constatações estão também nos protocolos dos alunos, apresentados nas Figuras 7, 8 e 9.

Figura 7: Reprodução do protocolo da tarefa 2 do A002

- Nenhuma dificuldade.

- Enunciado fácil de compreender.

Fonte: Arquivo da pesquisadora

Figura 8: Reprodução do protocolo da tarefa 2 do A003

Esse enunciado facilita a compreensão do aluno, já que ele manipularia a linguagem escrita para a construção figural e, em seguida, resolveria o exercício e construiria o gráfico.

Obs. Sair da linguagem escrita facilita a compreensão imediata do aluno.

Fonte: Arquivo da pesquisadora

Figura 9: Reprodução do protocolo da tarefa 2 do A007

Esse foi mais simples; não tive muita dificuldade.

Fonte: Arquivo da pesquisadora

Os protocolos revelam que os alunos reconhecem que o enunciado facilita a resolução e que o fato de essa transformação de representação oferecer um conteúdo de uma forma habitual para os alunos, ajuda a chegar à solução. Notamos, inclusive, no protocolo do aluno 004, que apesar de reconhecer que essa tarefa apresenta o caminho inverso da anterior, ele admite ter tido dificuldades na resolução, embora a tarefa seja de fácil interpretação. 
É o contrário do que se pede no exercício anterior, e acabei tendo dificuldades em contruí-lo. Para construí-lo, o aluno precisa ter um maior conhecimento do conteúdo para saber exatamente como proceder. Porém, com as informações por você passadas, ficou mais fácil de entender como construí-lo.

Fonte: Arquivo da pesquisadora

De fato, essa tarefa apresenta o mesmo conteúdo matemático da anterior, porém ela pode ser mais acessível aos alunos devido ao caminho da transformação dessa conversão. Isso fica confirmado, uma vez que Duval (2009) considera que em uma transformação de conversão, o objeto matemático continua a ser o mesmo, mas seu conteúdo é diferente quando se considera seu registro de representação.

Porém, podemos observar, nesse protocolo, que as dificuldades estão relacionadas a aspectos conceituais da Matemática. É clara a dificuldade dos alunos em associar o objeto matemático, função polinomial de primeiro grau, inserido no contexto da Física. Imaginamos que se porventura essa questão apresentasse uma função com variáveis expressas por y e x e solicitasse a construção gráfica, talvez os alunos tivessem mais facilidade para resolvê-la. Dessa forma, fica evidente que a articulação de conteúdos matemáticos nas aulas de Física ainda apresenta diversas fragilidades, pricipalmente quando ocorre, por meio de representações semióticas diferentes, a mobilização de mesmos objetos matemáticos. A tarefa 3, apresentada na Figura $11 \mathrm{em}$ seu enunciado na língua natural, tem também o registro algébrico, ou seja, a própria função horária do deslocamento. As alternativas solicitadas para resolução estão todas atreladas à função já fornecida. Nessa tarefa, a transformação presente é o tratamento, pois o aluno parte do registro algébrico e continua trabalhando nele.

Figura 11: Comanda da tarefa 3 do instrumento 3
3. Um carro movimenta-se segundo a função horária $\mathrm{S}=50+8 \mathrm{t}$ (no SI).
a) Qual a posição inicial e a velocidade do carro?
b) Qual a posição do carro no instante 20s?
c) Em que instante o carro passa pela posição $650 \mathrm{~m}$ ?
d) Que distância o carro percorre durante o $10^{\circ}$ segundo?

Fonte: Bonjorno et al., 2001, p. 26

Duval (2003) salienta que o tratamento é uma atividade de transformação de representações dentro de um mesmo registro semiótico; ele mesmo cita como exemplo a resolução de uma equação.

Nessa tarefa, nossa hipótese era de que os alunos apresentariam menor dificuldade por haver uma ação mais imediata de resolução, uma vez que o trabalho ocorre apenas no registro algébrico e não são necessárias mobilizações de conteúdos além daquelas previamente fornecidas.

Nas respostas a essa tarefa, diferentemente das anteriores, os alunos não realizaram muitas descrições sobre o grau de dificuldade, partiram da resolução 
imediata, ou seja, substituíram os valores na função e chegaram aos resultados. A maioria resolveu com êxito os itens "a", "b" e "c". Alguns alunos erraram a resposta ao item "d" por terem feito a substituição imediata do valor 10 s na variável tempo da função. Eles Seguiram a mesma sistemática dos itens anteriores e não observaram que o item "d" se referia à distância percorrida pelo móvel no $10^{\circ}$ segundo, ou seja, no intervalo de tempo entre 10 s e 11 s.

Figura 12: Protocolo da tarefa 3 do A002

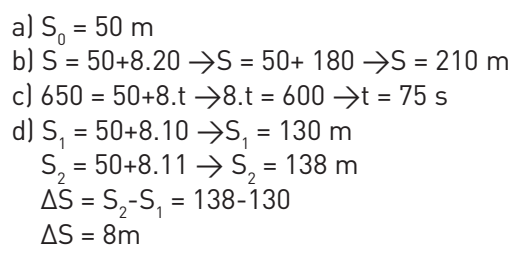

Dificuldades:

- Nenhuma, o enunciado está claro. 0 exercício é a manipulação de uma única função.

Fonte: Arquivo da pesquisadora

Figura 13: Reprodução do protocolo da tarefa 3 do $\mathrm{A003}$

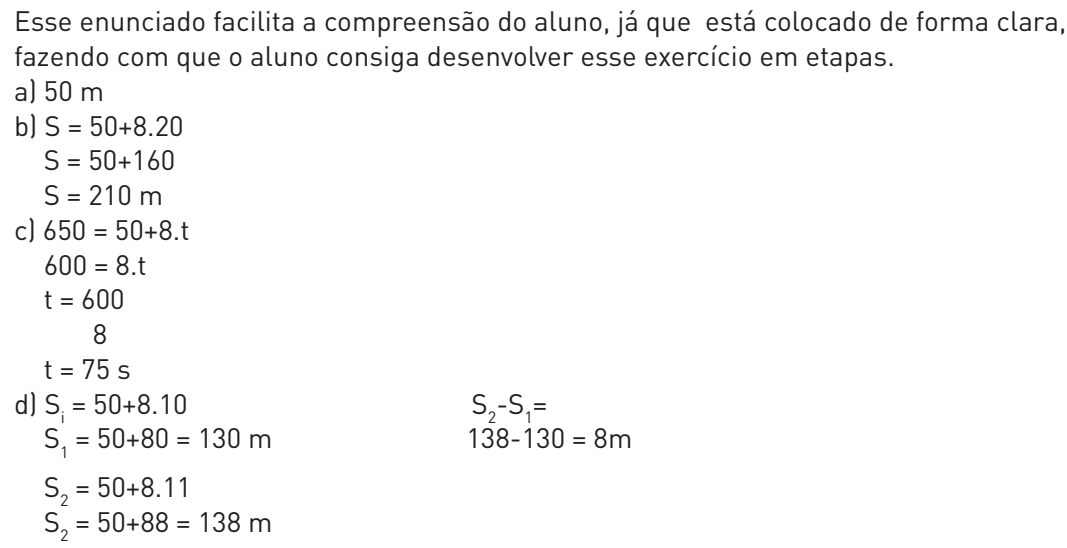

Segundo os protocolos apresentados nas Figuras 12 e 13, fica evidente que os alunos consideraram essa tarefa como uma "manipulação de fórmulas" e a resolveram facilmente.

Para Duval (2003), esse tipo de transformação, o tratamento, é muitas vezes, do ponto de vista "pedagógico", uma forma de procurar o melhor registro de representação a ser utilizado para que os alunos possam compreender uma situação.

Quando solicitamos, na comanda inicial do instrumento, que os alunos verificassem se a forma de apresentação do enunciado facilitava ou não a resolução 
da tarefa, tínhamos como objetivo que, mesmo implicitamente, os alunos observassem as diferentes representações envolvidas em cada tarefa, mesmo sem classificar tais transformações em tratamentos e conversões. Um passo importante é a própria verificação dos diferentes registros, pois esse fator indica se os alunos transitam por vários registros de representação em se tratando do mesmo objeto matemático.

Para Duval (2003, p.24), "os fenômenos cognitivos reveladores da atividade matemática concernem à mobilização de vários registros de representação semiótica e à conversão dessas representações”.

Nas tarefas que compuseram esse instrumento, utilizamos basicamente o mesmo objeto matemático (funções polinomiais de primeiro grau). A intenção era evidenciar que sua aprendizagem na Matemática não pode apresentar uma conotação tão distante que não a faça ser reconhecida na disciplina de Física. Mas, os resultados indicam que, em alguns casos, os alunos, embora compreendam o sentido de uma conversão, não reconhecem seu sentido de volta. Sobre a responsabilidade desse fato, Duval (2003, p.20) aponta que "geralmente, no ensino, um sentido de conversão é privilegiado, pela idéia de que o treinamento num sentido estaria automaticamente treinando a conversão no outro sentido". Assim, nem sempre o trabalho partindo, por exemplo, da representação algébrica para a representação gráfica, garante que o aluno, em situações futuras, tenha clareza, ao partir da representação gráfica para a representação algébrica.

\section{CONSIDERACְÕES FINAIS}

Com base nas análises realizadas, fica evidente que a passagem de um registro de representação a outro, em algumas situações, ocupa um papel de fragilidade perante o aluno, na mobilização de conteúdos matemáticos e também no reconhecimento do objeto matemático que está sendo trabalhado.

A teoria de Duval $(1993,2009)$ possibilita ao professor entender o funcionamento das dificuldades apresentadas pelos alunos e saber em que problemas esbarram quando não conseguem resolver determinadas tarefas. Ficou evidente, em nossa pesquisa, que os alunos conseguem trabalhar com facilidade na resolução de uma tarefa que vai do registro algébrico para o gráfico, porém, revelaram dificuldades em solucionar a tarefa que solicitava o caminho inverso.

Com base nessas considerações, é possível concluir que a aprendizagem está associada ao fato de o aluno reconhecer o mesmo objeto matemático em diferentes representações, e que esse reconhecimento é responsável pelo sucesso dos alunos nas mobilizações de conteúdos matemáticos em diferentes situações. Isso fica evidente na disciplina de Física, uma vez que esta, apesar de seu forte caráter conceitual, depende também de resoluções de tarefas que necessitam da articulação e do reconhecimento de conteúdos matemáticos.

Com base nessa teoria e na análise da pesquisa desenvolvida, pudemos observar também que a passagem de um sistema de representação para outro ou 
a mobilização simultânea de vários sistemas de representação, no decurso do mesmo processo intelectual, podem ser fenômenos familiares e frequentes na atividade matemática, porém, não são espontâneos ou evidentes para a maioria dos estudantes.

Assim, nas atividades de ensino, deve-se considerar a diversidade dos registros de representação semiótica envolvidos em uma determinada situação. Dessa forma, observamos, nessa teoria, um caminho que possibilita a professores a análise da dificuldade dos alunos em relação a um determinado conteúdo e possibilita a elaboração, até mesmo, de sequências didáticas que façam evoluir a concepção dos alunos num determinado nível de ensino.

Verificamos, também, que mesmo em tarefas que apresentam uma transformação de tratamento, os alunos apresentam dificuldades que são resultantes de problemas conceituais quanto ao entendimento da disciplina de Física e também a utilização inadequada da Matemática.

\section{REFERÊNCIAS}

BONJORNO, R. A. et al. Física completa. Volume único: ensino médio. 2. ed. São Paulo: FTD, 2001. DUVAL, R. Registres de représentation sémiotique et fonctionnement cognitif de la pensée. Annales de Didactiques et de Sciences Cognitives, Paris, v. 5, p. 37-65,1993.

. Registros de representações semióticas e funcionamento cognitivo da

compreensão em Matemática. In: MACHADO, S. D. A. (Org.). Aprendiragem em Matemática: registros de representação semiótica. Campinas, SP: Papirus, 2003. p.11-33.

. Semiósis e pensamento humano: registros semióticos e aprendizagens intelectuais. Trad. de Lênio Fernandes Levy e Marisa Rosâni Abreu da Silveira. São Paulo: Editora Livraria da Física, 2009.

SANTOS, C. A. B. O ensino da Física na formação do professor de Matemática. 2010. 189 f. Tese (Doutorado em Ensino de Ciências e Matemática) - Universidade Cruzeiro do Sul, São Paulo, 2010.

Data do Recebimento: 12/05/2011

Data de Aprovação: 05/04/2012

Data da Versão Final: 05/05/2012 
